\title{
New-Onset Diabetes after Transplant (NODAT)
}

\section{Maskey R}

\author{
Department of Internal Medicine \\ BPKIHS, Dhran, Nepal \\ Corresponding Author \\ Robin Maskey \\ Department of Internal Medicine \\ BPKIHS, Dhran, Nepal \\ E-mail: drmaskey@gmail.com
}

\section{Citation}

Maskey R. New-Onset Diabetes after Transplant (NODAT). Kathmandu Univ Med J 2014;48(4):301-5.

\begin{abstract}
New onset diabetes mellitus after transplantation (NODAT) is a well known complication following solid organ transplantation and has been reported to occur in $4 \%$ to $25 \%$ of renal transplant recipients, $2.5 \%$ to $25 \%$ of liver transplant recipients, hepatitis C virus (HCV) infection between $40 \%$ and $60 \%$ and $2 \%$ to $53 \%$ of all solid organ transplants. This variation in the reported incidence may be because of lack of a universal agreement on the definition of NODAT, the duration of followup, and the presence of modifiable and non-modifiable risks factors. Moreover, reduced patient survival and accelerated graft loss have been reported with NODAT. In our country also there is increasing in number of kidney transplants patients and along with that there is chance of development of NODA. It is better to detect the NODATS early. So in this article I tried to presents an overview of the literature on the current diagnostic criteria for NODAT and discuss suggested risk factors for the development of NODAT, its potential pathogenic mechanisms, and its impact on post-transplant outcomes after solid organ transplantation.
\end{abstract}

\section{KEYWORDS}

New onset diabetes after transplantation, review and management

\section{INTRODUCTION}

New-onset diabetes after transplantation (NODAT) refers to diabetes that occurs in previously nondiabetic persons after solid-organ transplantation, bone marrow and hematopoietic stem cells. ${ }^{1,2}$ It is also called as Secondary type of diabetes mellitus since it develops secondary to use of immunosuppressant's.

\section{Definition of NODAT}

The concept of NODAT was not well known for last fifty years and was called as post transplantation diabetes mellitus. The most commonly used clinical definition was the requirement of insulin post transplantation (minimum of 30 days). Now International Consensus Guidelines for the diagnosis of NODAT 2003 recommended that should be based on the American Diabetes Association (ADA) criteria for type 2 diabetes, ${ }^{3,4}$ which are as follows:

-Fasting plasma glucose (FPG) $=7.0 \mathrm{mmol} / \mathrm{L}(126 \mathrm{mg} / \mathrm{dL})$ with no calorie intake for at least 8 hours and / or

- A 2 hour plasma glucose during an OGTT (2 hr PG) = $11.1 \mathrm{mmol} / \mathrm{L}(200 \mathrm{mg} / \mathrm{dL})$, or
- A casual plasma glucose $=11.1 \mathrm{mmol} / \mathrm{L}(200 \mathrm{mg} / \mathrm{dL})$, on 3 or more occasions.

$\mathrm{HbA} 1 \mathrm{C}$ assay is not used because end stage renal disease (ESRD) patients and newly transplanted kidney patients are frequently associated with anemia (due to surgical blood loss, iron deficiency, immunosuppressive drugs, graft dysfunction, and abrupt discontinuation of erythropoietin administration) which leads to spurious $\mathrm{A} 1 \mathrm{C}$ results. ${ }^{5,6}$

\section{Natural History and Incidence of NODAT}

The first cases of NODAT were described in 1964 after a liver transplant by Thomas Starz, ${ }^{7}$ which occurs mainly during the first 6 months post transplantation during treatment with high doses of immunosuppressant. After 6 months, the annual incidence of diabetes is similar to that observed in patients on the waiting list i.e., $6 \%$ per year. $^{7}$

The incidence of NODAT varies among the recipients of different organ transplants and over different post transplant intervals as shown in table. 1 below. The most accurate incidence of NODAT under calcineurin inhibitor 
(CNI) therapy according to the prospective study of Vincenti et al., ${ }^{8} 20.5 \%$ within the first 6 months post renal transplantation. In some patients the risk of developing NODAT has been seen up to 15 years after transplantation. ${ }^{9}$

Table 1. Overall incidence of NODAT among various types of Transplants Recipients

\begin{tabular}{|c|c|}
\hline Types of Transplantation & Overall Incidence \% \\
\hline New onset diabetes after transplantation ${ }^{10}$ & $2-53 \%$ \\
\hline Renal transplant ${ }^{11}$ & $4-25 \%$ \\
\hline Liver transplant ${ }^{12}$ & $2.5-25 \%$ \\
\hline Heart transplant ${ }^{13}$ & $4-40 \%$ \\
\hline Lung transplant ${ }^{14}$ & $30-35 \%$ \\
\hline HCV infected liver transplant ${ }^{15}$ & $40-60 \%$ \\
\hline
\end{tabular}

\section{Risk Factors of NODAT}

The risk factors of NODAT are classified as non-modifiable, modifiable or potentially modifiable, the former helps to facilitate the identification of high risk individuals, and the latter two helps to optimize the management of NODAT.

\section{Non Modifiable}

Age:

As per United States Renal Data System (USRDS) and the Organ Procurement Transplant Network/United Network of Organ Sharing (OPTN/UNOS) there was $90 \%$ increase of relative risk (RR) in renal transplant patients aged 45-59 yrs and a $160 \%$ increase in $\geq 60$ years of age (versus $18-44$ years)..$^{16}$ So, older age is a strong independent risk factor of NODAT.

\section{Race/ethnicity}

There have been few literatures suggesting that African Americans and Hispanics are at increased risk for developing NODAT compared to whites. The RR of NODAT is increased by $32-68 \%$ in black patients and by $35 \%$ in Hispanic patients in comparison with white patients. ${ }^{17}$

\section{Family history of diabetes mellitus}

There is strong evidence suggesting that individuals with a family history of diabetes among first-degree relatives have sevenfold increased risk of developing NODAT. ${ }^{18}$

\section{Other non-modifiable risk factors include}

- Recipient male gender

- Presence of certain human leukocyte antigens (HLA) such as HLA A30, B27, and B42

- Increasing HLA mismatches

- Donor-recipient (DR) mismatch; deceased donor kidneys; male donor; and acute rejection history. ${ }^{19}$

- Polycystic kidney disease has been suggested to confer an increased risk of developing diabetes after renal transplantation in some studies but not in others. ${ }^{20-23}$

\section{Modifiable Risk Factors}

Obesity

Overweight or obese patients have a higher risk of developing NODAT, with an RR of 1.4 for patients with a BMI between 25 and $30 \mathrm{~kg} / \mathrm{m}^{2}$ and an RR of 1.7-1.8 for patients with a BMI $>30 \mathrm{~kg} / \mathrm{m}^{2} .^{24}$ The pattern of body fat distribution especially intra-abdominal fat or waist-tohip ratio have been found to be important risk factors for NODAT than total body weight or BMI. ${ }^{19}$

\section{Hypertriglyceridemia/hypertension}

Multivariate analysis have shown that among all the pretransplant metabolic syndrome components, only low density lipoprotein was independently associated with the development of NODAT. ${ }^{25}$

\section{Proteinuria}

A single-center study has shown an association between proteinuria five days after transplantation and the development of NODAT. ${ }^{26}$ But, these findings have been challenged because proteinuria on day five may just reflect the highly concentrated urine associated with hyperglycemia induced osmotic diuresis from the early posttransplant, use of high dose corticosteroids or residual native kidney proteinuria. Moreover it has been shown that immediate posttransplant proteinuria generally resolves several weeks after transplantation. ${ }^{27}$

\section{Hypomagnesemia}

The post transplantation hypomagnesemia was found to be an independent predictor of NODAT in both renal and liver transplant especially induced by CNIs (more common with tacrolimus), due to renal magnesium wasting occurring through transcriptional inhibition of the renal magnesium transporter in the distal collecting tubule.

\section{Impaired glucose tolerance before transplantation}

Cosio et al demonstrated that higher pre transplant glucose is a risk factor for NODAT at one year. ${ }^{9}$ Among patients with IFG pretransplant, $70 \%$ had hyperglycemia at one year (IFG $43 \%$ and NODAT $27 \%$ ).

\section{Potentially Modifiable Risk Factors}

\section{HCV-associated NODAT}

The association between HCV infection and IFG, or the development of overt type 2 diabetes mellitus in the general population, has long been suggested. Potential mechanisms for the diabetogenic effect of HCV infection include insulin resistance; decreased hepatic glucose uptake and glycogenesis; and direct cytopathic effect of the virus on pancreatic cells. ${ }^{28}$ Baid and colleagues ${ }^{29}$ have shown that the presence of $\mathrm{HCV}$ infection was independently associated with a $62 \%$ increase in insulin resistance $(P=$ 0.0005). 


\section{Cytomegalovirus-associated NODAT}

The link between cytomegalovirus (CMV) infection and the development of NODAT was first reported in 1985 in a renal transplant recipient. ${ }^{30}$ Patients with active CMV infection had a significantly lower median insulin release compared to their CMV negative counterparts, suggesting that impaired pancreatic $\beta$ cell insulin release may be involved in the pathogenic mechanism of CMV-associated NODAT. It is speculated that CMV-induced release of pro inflammatory cytokines may lead to apoptosis and functional disturbances of pancreatic $\beta$-cells. ${ }^{31}$

Also diseases like chronic renal failure, hypovitaminosis D, hyperparathyroidism, multiple transplants, and repeated interventions for transplant rejections may create a putative diabetogenic environment in some post transplant patients. ${ }^{32}$

\section{Pathogenesis of NODAT}

Starlz was the first to described the role of corticosteroids in NODAT in 1964 in renal transplant recipients. ${ }^{33}$ The diabetogenic effect of glucocorticoids is mainly due to insulin resistance, mediated by both impaired insulindependent glucose uptake in the peripheral tissues and enhanced gluconeogenesis in the liver. High-dose glucocorticoid regimens used during the 1970s were associated with a very high incidence of so-called "steroid diabetes," which declined when cyclosporine was introduced as an immunosuppressant in the 1980s. A 0.01 $\mathrm{mg} / \mathrm{kg} / \mathrm{d}$ increase in prednisolone dose was associated with a $5 \%$ risk of developing NODAT. ${ }^{34}$

Calcineurin Inhibitors(CNIs) are diabetogenic by inducing a defect in insulin secretion, ${ }^{35}$ by interfering with the nuclear factor of activated T-cell signaling in pancreatic $\beta$-cells. This pathway triggers the expression of genes critical for $\beta$-cell function, including at least six genes mutated in hereditary forms of monogenic diabetes.

Tacrolimus induces a reversible suppression of insulin secretion at the level of insulin mRNA transcription, mediated by the binding of the drug to FK506 binding protein-12 and a subsequent inhibition of calcineurin in the $\beta$-cells. ${ }^{36}$ Maes and colleagues showed that a high tacrolimus trough level, ${ }^{37}$ particularly a level of greater than $15 \mathrm{ng} / \mathrm{mL}$ in the first month after transplant, was a significant risk factor for persistent IFG or diabetes mellitus beyond the first year after transplantation.

Potential mechanisms of the diabetogenic effect of HCV infection include insulin resistance, decreased hepatic glucose uptake and glycogenesis, and a direct cytopathic effect of the virus on pancreatic beta cells. ${ }^{38}$

The link between CMV infection and the development of NODAT was first reported in 1985 in a renal transplant recipient. ${ }^{39}$ It is speculated that CMV-induced release of proinflammatory cytokines may lead to apoptosis and functional disturbances of pancreatic b cells. ${ }^{32}$

\section{Sequelae of NODAT}

In addition to the risk of developing the well-known long term complications of diabetes, NODAT also identifies patients at high risk for adverse clinical outcomes: loss of the renal allograft, infections, cardiovascular events, and increased mortality among renal transplant patients. ${ }^{40,41}$

Among liver transplant recipients, NODAT is associated with increased cardiovascular morbidity and mortality, more fatal infections more neuropsychiatric complications, higher rejection rates, and poorer graft survival. ${ }^{42}$

Among lung transplant recipients, cytomegalovirus (CMV) infection and acute rejection episodes were observed more frequently among patients who developed NODAT compared with their normoglycemic counterparts. ${ }^{43}$

\section{Management of NODAT}

\section{Pre transplant Evaluation}

Currently, pre transplant risk assessment should be based on the phenotype and the medical history of the patient. The following factors associated with a higher risk of NODAT should be considered:

- an age $>45$ years old,

- a familial history of type 2 diabetes,

- a personal history of NODAT with previous graft or a gestational diabetes,

- $\quad$ IFG, impaired glucose tolerance, criteria for metabolic syndrome, a $\mathrm{BMI}>30 \mathrm{~kg} / \mathrm{m}^{2}$,

- $\quad$ and a positive hepatitis $C$ serology.

The screening should include an evaluation of the glucose metabolism status by FPG and/or OGTT. A recent large study ( $N=889$ ) has underlined the low sensitivity of FPG in detecting pre transplant glucose metabolism abnormalities in patients with ESRD because of insulin resistance. An FPG screening should be performed in all candidates, followed ideally by an OGTT in patients with FPG between 92 and $125 \mathrm{mg} / \mathrm{dL}$ ( $\pm 50 \%$ of patients). This should allow the identification of $>80 \%$ of pre transplant diabetes. ${ }^{44}$

The use of Glycoslated hemoglobin (HbA1c) is not recommended for the screening given the low sensitivity of the test in ESRD patients. ${ }^{5}$ Patients should be screened for risk factors before transplantation in order to prospectively tailor their immunosuppression and minimize the risk of NODAT.

Patients at risk should be counseled on the importance of lifestyle intervention, including weight control, diet, and physical activity; as such strategy is efficient in patients at risk for type 2 diabetes.

\section{Post transplant Monitoring:}

Recent guidelines recommend screening all kidney transplant recipients with FPG, OGTT, and/or A1C assay at 
least weekly for 4 weeks, every 3 months for 1 year, and annually thereafter. ${ }^{45}$

The screening with FPG levels should be performed at the intervals described above, and an OGTT could be considered in patients with IFG at 3 and 6 months (as the higher risk of NODAT is present during the first 6 months after transplantation). Additionally, A1C could be assayed at 3 and 6 months, and then yearly, to improve NODAT diagnostic accuracy.

\section{Pharmacological Management of Hyperglycemia}

Currently, it is considered that patients with an A1C assay $\geq 6.5 \%$ should start glucose-lowering agents. As for type 2 diabetes, a stepwise approach should be adopted.

The first step includes dietetic recommendations (weight control, diet, and exercise).

The second step is the initiation of an oral agent in monotherapy. The choice of the drug should take into account the patient-specific factors, graft function (some drugs or active metabolites are eliminated by the kidney), specific side effects, and potential pharmacokinetic interactions with immunosuppressive drugs (mainly interaction with $\mathrm{CNI}$ or $\mathrm{m}$-TOR through metabolization by cytochrome $\mathrm{P} 450$, family 3 , subfamily $A$, polypeptide $4 / 5$ [CYP3A4/5]). Almost all oral agents can be used, except for the first-generation sulfonylureas (because they accumulate and induce hypoglycemic episodes) and biguanides (because they induce lactic acidosis). Biguanides should be avoided if the glomerular filtration rate is $<60$ $\mathrm{mL} / \mathrm{min}$. Gliquidone, the most-prescribed agent for kidney transplants in our institution, is efficient, well tolerated,

\section{REFERENCES}

1. Viberti G. Diabetes mellitus: a major challenge in transplantation. Transplant Proc 2001; 33(Suppl 5A):3S-7S.

2. Woo M, Przepiorka D, Ippoliti C, et al. Toxicities of tacrolimus and cyclosporine A after allogeneic blood stem cell transplantation. Bone Marrow Transplant 1997;20:1095-8.

3. Genuth S, Alberti KG, Bennett $P$, et al. Expert Committee on the Diagnosis and Classification of Diabetes Mellitus. Follow-up report on the diagnosis of diabetes mellitus. Diabetes Care 2003;26:3160-3167.

4. American Diabetes Association. Diagnosis and classification of diabetes mellitus. Diabetes Care 2010;33(Suppl. 1):S62-S69.

5. Sharif A, Baboolal K. Diagnostic application of the $A(1 \mathrm{c})$ assay in renal disease. J Am Soc Nephrol 2010;21:383-385.

6. International Expert Committee. International Expert Committee report on the role of the $\mathrm{A} 1 \mathrm{C}$ assay in the diagnosis of diabetes. Diabetes Care 2009;32:1327-1334.

7. Woodward RS, Schnitzler MA, Baty J, et al. Incidence and cost of new onset diabetes mellitus among U.S. wait-listed and transplanted renal allograft recipients. Am J Transplant 2003;3:590-8.

8. Vincenti F, Friman S, Scheuermann E, et al. DIRECT (Diabetes Incidence after Renal Transplantation: Neoral C Monitoring Versus Tacrolimus) Investigators. Results of an international, randomized trial comparing glucose metabolism disorders and outcome with cyclosporine versus tacrolimus. Am J Transplant 2007;7:1506-1514. and has no interaction with immunosuppressive drugs.

The third step is a combination of oral agents with different mechanisms of actions. Combination therapy has not been investigated and compared in kidney allograft recipients. The last step is the initiation of insulin with or without oral agents. If individualized goals for glucose control are not achieved within 2-4 months, lifestyle interventions should be reassessed and patients should move to the next step

The last step is the initiation of insulin with or without oral agents. If individualized goals for glucose control are not achieved within 2-4 months, lifestyle interventions should be reassessed and patients should move to the next step.

\section{CONCLUSION}

NODAT is associated with a higher risk of complications, such as infections and cardiovascular disease - So, representing a higher life threatening risk and a higher cost for the Health System. So, we should identify the risk factors for NODAT and with early diagnosis combined with appropriate therapy will results in the success of the procedure as far as patient survival and transplantation durability.

Future Aspect: Further studies are required to ascertain the current incidence, prevalence and natural history of NODAT in order to identify more effective strategies for prevention and management which include the development of immunosuppressive regimens with minimal diabetogenic effects, determination of the role of glycemic control on graft survival, and interventions for primary prevention of NODAT.

9. Cosio FG, Resavento TE, Osei K, Henry ML and Ferguson RM. Posttransplant diabetes ellitus: increasing incidence in renal allograft recipients transplanted in recent years. Kidney Inter. 2001; 59: 732- 737.

10. Davidson J, Wilkinson A, Dantal J, et al. International Expert Panel. New-onset diabetes after transplantation: 2003 International Consensus Guidelines. Proceedings of an international expert panel meeting. Barcelona, Spain, 19 February 2003. Transplantation 2003;75(Suppl.):SS3-SS24

11. Kasiske BL, Snyder JJ, Gilbertson D, Matas AJ 2003 Diabetes mellitus after kidney transplantation in the United States. Am J Transplant 3:178-185.

12. Pageaux GP, Faure S, Bouyabrine $H$, Bismuth M, Assenat E. Long-term outcomes of liver transplantation: diabetes mellitus. Liver Transpl 2009;15:S79-S82.

13. Ye $X$, Kuo HT, Sampaio MS, Jiang $Y$, Reddy $P$, Bunnapradist S. Risk factors for development of new-onset diabetes mellitus in adult heart transplant recipients. Transplantation 2010;89:1526-32.

14. Silverborn $M$, Jeppsson $A$, Mårtensson G, Nilsson F. Newonset cardiovascular risk factors in lung transplant recipients. J Heart Lung Transplant 2005; 24:1536-1543.

15. Knobler H, Stagnaro-Green A, Wallenstein S et al. Higher incidence of diabetes in liver transplant recipients with hepatitis C. J Clin Gastroenterol. 1998;26:30-33. 
16. Kasiske BL, Snyder JJ, Gilbertson D, Maras AJ. Diabetes mellitus after kidney transplantation in the United States. Am J Transplant. 2003;3(2): 178-185.

17. Sulanc E, Lane JT, Puumala SE, Groggel GC, Wrenshall LE, Stevens RB. New-onset diabetes after kidney transplantation: an application of 2003 International Guidelines. Transplantation. 2005;80(7):945-952.

18. Davidson J, Wilkinson AH, Dantal J. New-onset diabetes after transplantation: 2003 International Consensus Guidelines. Transplantation. 2003; 7:SS3-SS24.

19. Pham PT, Danovitch GM, Pham PC. The medical management of the renal transplant recipient. In: Johnson RJ, John Feehally, editors. Comprehensive Clinical Nephrology, $3^{\text {rd }}$ ed. Philadelphia, PA: Mosby; 2007:1085-1101.

20. Hamer RA, Chow CL, Ong AC, Mckane WS. Polycystic kidney disease is a risk factor for new-onset diabetes after transplantation. Transplantation. 2007;83:36-40.

21. Ducloux D, Motte G, Vautrin P, Bresson-Vautrin C, Rebibou JM, Chalopin JM. Polycystic kidney disease as a risk factor for posttransplant diabetes mellitus. Nephrol Dial Transplant. 1999;14: 1244-6.

22. De Mattos AM, Olyaei AJ, Prather JC, Golconda MS, Barry JM, Norman DJ. Autosomal dominant polycystic kidney disease as a risk factor for diabetes mellitus following transplantation. Kidney Int. 2005;67: 714-20.

23. Hjelmesaeth J, Hartmann A. Insulin resistance in patients with adult polycystic kidney disease. Nephrol Dial Transplant. 1999;14(10): 2521-2.

24. Bonato V, Barni R, Cataldo D, et al. Analysis of posttransplant diabetes mellitus prevalence in a population of kidney transplant recipients. Transplant Proc. 2008;40(6):1888-90.

25. Eckel RH. Mechanisms of the components of the metabolic syndrome that predispose to diabetes and atherosclerotic CVD. Proc Nutrition Soc. 2007;66(1):82-95.

26. Kuypers DR, Claes K, Bammens B et al. Early clinical assessment of glucose metabolism in renal allograft recipients: diagnosis and prediction of post-transplant diabetes mellitus. Nephrol Dial Transplant. 2008; 23(6):2033-42.

27. Myslak $M$, Amer $H$, Morales $P$ et al. Interpreting post-transplant proteinuria in patients with proteinuria pre-transplant. $A m \mathrm{~J}$ Transplant. 2006;6(7):1660-5.

28. Bloom RD, Lake JR. Emerging issues in hepatitis C virus-positive liver and kidney transplant recipients. Am J Transplant. 2006;6(10): 2232-7.

29. Baid S, Cosimi AB, Farrell ML et al. Posttransplant diabetes mellitus in liver transplant recipients: risk factors, temporal relationship with hepatitis $C$ virus allograft hepatitis, and impact on mortality. Transplantation. 2001;72:1066-1072.

30. Lehr H, Jao S, Waltzer WC, Anaise D, Rappaport FT. Cytomegalovirus induced diabetes mellitus in a renal transplant recipient. Transplant Proc. 1985;17(5):2152-4.
31. Hjelmesaeth J, Muller F, Jenssen $T$, Rollag $H$, Sagedar S, Hartmann A. Is there a link between cytomegalovirus infection and newonset posttransplant diabetes mellitus? Potential mechanisms of virus induced $\beta$-cell damage. Nephrol Dial Transplant. 2005;20(11): 2311-5.

32. Corica F, Corsonello A, lentile $\mathrm{R}$ et al. Serum ionized magnesium levels in relation to metabolic syndrome in type 2 diabetic patients. J Am Coll Nutr 2006;25:210-5.

33. Jindal RM, Revanur VK, Jardine AG. Immunosuppression and diabetogenicity. In: Hakim N, Stratta R, Gray D, editors. Pancreas and islet transplantation. $1^{\text {st }}$ ed. New York: Oxford University Press; 2002. p. $247-75$

34. Hjelmesaeth J, Hartmann A, Kofstad J et al. Tapering off prednisolone and cyclosporine the first year after renal transplantation: the effect on glucose tolerance. Nephrol Dial Transplant 2001;16:829-35.

35. Soleimanpour SA, Crutchlow MF, Ferrari AM, et al. Calcineurin signaling regulates human islet beta-cell survival. I Biol Chem 2010;285:40050-40059.

36. Tamura K, Fujimura T, Tsutsumi $\mathrm{T}$ et al. Transcriptional inhibition of insulin by FK506 and possible involvement of FK506 binding protein-12 in pancreatic beta-cell. Transplantation 1995;59:1606-13.

37. Maes BD, Kuypers D, Messiaen T et al. Post-transplant diabetes mellitus in FK-506-treated renal transplant recipients: analysis of incidence and risk factors. Transplantation 2001; 72(10):1655-61.

38. Bloom RD, Lake JR. Emerging issues in hepatitis $C$ virus-positive liver and kidney transplant recipients. Am J Transplant 2006;6:2232-7.

39. Lehr H, Jao S, Waltzer WC et al. Cytomegalovirus-induced diabetes mellitus in a renal transplant recipient. Transplant Proc 1985;17: 2152-4.

40. Hjelmesaeth J, Hartmann A, Leivestad T, Holdaas H, Sagedal S, Olstad $M$ et al. The impact of early diagnosed new-onset post-transplantation diabetes mellitus on survival and major cardiac events. Kidney Int 2006;69:588-95.

41. Moon JI, Barbeito R, Faradji RN, Gaynor JJ, Tzakis AG. Negative impact of new onset diabetes mellitus on patient and graft survival after liver transplantation: long-term follow-up. Transplantation 2006;82: 1625-8.

42. John PR, Thuluvath PJ. Outcome of patients with new-onset diabetes mellitus after liver transplantation compared with those without diabetes mellitus. Liver Transp/ 2002;8:708-13.

43. Ollech JE, Kramer MR, Peled N, Ollech A, Amital A, Medalion B et al. Post-transplant diabetes mellitus in lung transplant recipients: incidence and risk factors. Eur J Cardiothorac Surg 2008;33:844-8.

44. Wilkinson A, Davidson J, Dotta F et al. Guidelines for the treatment and management of new-onset diabetes after transplantation. Clin Transplant 2005;19:291-8.

45. Kidney Disease: Improving Global Outcomes (KDIGO) Transplant Work Group. KDIGO clinical practice guideline for the care of kidney transplant recipients. Am J Transplant 2009;9(Suppl. 3):S1-S155 